\title{
Morphological status of multipolar neurons in the lateral cortical area of the telencephalon of a catfish, Clarias batrachus: A Golgi study
}

\author{
Banalata Mohanty, Anil Kumar Ojha* \\ Department of Zoology, Faculty of Science, University of Allahabad, Prayagraj, India.
}

\begin{tabular}{l}
\hline ARTICLE INFO \\
\hline Article history: \\
Received on: May 14, 2021 \\
Accepted on: June 25, 2021 \\
Available online: September 01, 2021 \\
\hline
\end{tabular}

Key words:

Multipolar neuron, lateral cortical area, telencephalon, Clarias

batrachus, Golgi staining,

dendrite, dendritic spine

\begin{abstract}
The present study explored the morphological features of multipolar neurons in the lateral cortical area of the telencephalon of a catfish, Clarias batrachus, employing Golgi staining. In C. batrachus, the multipolar neurons have round to multiangular soma with axon emerged adjacent to either basal or apical dendrites. Branched apical and basal dendrites are of various thicknesses with few dendritic spines on them. Multipolar neurons have shown uniform distribution in both the center and toward the boundary of the lateral cortical area. The morphological features and position suggest that the role of this neuronal type in maintaining the local circuit as well as in transmitting information acting as projection neurons to the adjacent telencephalic region.
\end{abstract}

\section{INTRODUCTION}

Neurons are the highly polarized cell types, which possess structurally and functionally different processes, and extended from the soma that mediates information flow through the nervous system such as dendrites and axons. An axon is a thread-like process that transmits signals to other neurons with the release of neurotransmitters that emerge from the soma, which is a single long process. From the soma emerge multiple branched processes known as dendrites. Dendrites contain neurotransmitter receptors to collect signals from adjacent connected neurons [1]. Neurons in which more than three dendrites arise from the soma and radiate in different angles or at different poles are known as multipolar neurons and their axon terminals contain pleiomorphic synaptic vesicles [2], a synaptic feature usually associated with an inhibitory neurotransmitter [3]. In mammals, after pyramidal neurons, the second position is acquired by multipolar neurons [4].

Multipolar neurons have a different structural configuration like long-tufted descending axons, elongated large axonal arborizations,

\footnotetext{
*Corresponding Author

Anil Kumar Ojha, Department of Zoology, Faculty of Science, University of Allahabad, Prayagraj, India. E-mail: anilojha4u@gmail.com
}

small soma with short ascending, descending, or local axons, or with local or extended axonal arborizations in diverse layers of the cortex of mammals [5] and different cortical regions in the different genera of mammals [4,6-9]. Multipolar neurons are also well documented in other vertebrate classes - birds [10-13], reptiles [14-17], and amphibia [18,19] - but in fishes, there are limited studies on telencephalic neuronal morphology [20-22], including the lateral cortical area $[21,22]$. The telencephalic lateral cortical area of fish is equivalent to the mammalian hippocampus [23] where multipolar neurons are present [24]. However, in fishes, no morphological details on multipolar neurons are available according to relative abundance, soma shape, soma size, axon length, the diameter of dendrites, and spine density. So, in the present study, we elucidated these morphological parameters of multipolar neurons in the lateral cortical area of the telencephalon of a catfish Clarias batrachus, and further discuss with other reported vertebrate multipolar neurons.

\section{MATERIALS AND METHODS}

\subsection{Animal Model}

Clarias batrachus, a freshwater air-breathing catfish, lives in stagnant ponds, swamps, and hypoxic water with occasional trips 
to the surface to take mouthful of air, and are carnivorous in nature. Clarias batrachus has economic importance for human beings as a food and also has medicinal value [25]. Since these fish survive in laboratory conditions and are mostly used in experiments in India, we used 10 adult $C$. batrachus, measuring 200-250 $\mathrm{mm}$ in length and weighing 200-250 g. Fishes were collected from the market of Prayagraj (formerly Allahabad, $25^{\circ} 28^{\prime} \mathrm{N}, 81^{\circ} 54^{\prime} \mathrm{E}$ ) and acclimatized for 15 days in laboratory condition.

\subsection{Golgi-Colonnier Method}

Fishes were anesthetized by giving cold treatment and perfused with the $0.1 \mathrm{M}$ phosphate buffer mixed with $4 \%$ of paraformaldehyde to fix the whole body with all vital organs including the brain. After perfusion, the brains were removed from the skull and again fixed in paraformaldehyde mixed $0.1 \mathrm{M}$ phosphate buffer for 24 hours. After fixation, the brains were washed with gentle tap water for 18 24 hours then the brains were prechromed in $2.5 \%-3 \%$ potassium dichromate. Brains were then kept in a $2 \%$ potassium dichromate and with $5 \%$ glutaraldehyde solution for chromation of 3 days. After chromation, the brains were transferred in $1 \%$ silver nitrate solution at normal room temperature for 2 days. Both chromation and silver steps were repeated thrice. After the completion of the third and final silver step, the brains were dehydrated by graded series of alcohol before being fixed in paraffin wax (congealing point $58^{\circ}-60^{\circ} \mathrm{C}$ ). Sections of $100 \mu \mathrm{m}$ thick were cut with the help of a sliding microtome and were dehydrated in $100 \%$ alcohol before being washed in xylene, after which they were mounted and coverslipped using DPX.

\subsection{Statistical Data Analysis}

Neurons were observed using a $40 \times$ magnification objective. Camera lucida of neurons were made with the support of a camera lucida equipment attached to the simple laboratory light microscope. Photographs were captured with the assistance of a computer-aided research microscope, a Nikon Eclipse 80i (Software, ACT-1) camera. All the photographs and camera lucida drawings were edited with the help of Adobe Photoshop 7.0.

All the neuronal parameters were measured with the support of Image J Software. Dendritic spine density was calculated by counting visible spines alongside $10 \mu \mathrm{m}$ lengths of apical and basal dendrites from 30 neurons. The true number of estimated dendritic spines was calculated as described by Feldman and Peters [26]. Dendrites whose picture is clear and a plane parallel to the section were only considered for analysis. Quantitative measurement of morphological parameters was calculated with the assistance of the statistical software GraphPad PRISM version 5.1 (San Diego, CA) and differences were tested at a 95\% significant level $(p<0.05)$.

\section{RESULTS AND DISCUSSION}

\subsection{Relative Frequencies of Multipolar Neurons}

The present data of the percentage of multipolar neurons in $C$. batrachus (Fig. 1) shows that these cell types are the principal elements in the lateral cortical area of the telencephalon. Multipolar neurons accounting for $31.49 \%$ of the total neuronal population ( $n$ $=416$ ) outnumbered all other neurons that are unipolar, bipolar,

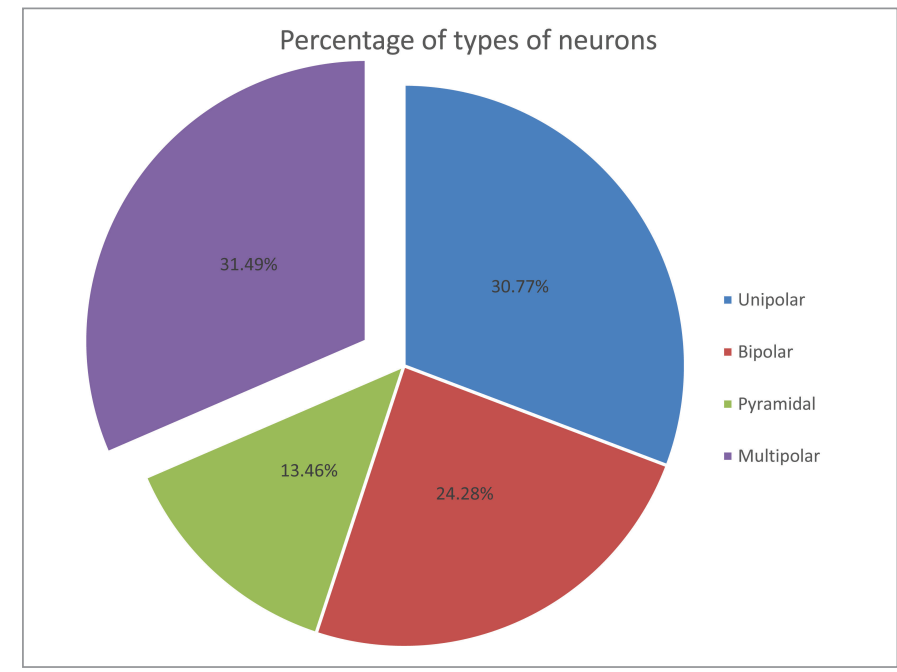

Figure 1: Pie diagram showing the percentage of different types of neurons observed in the lateral cortical area of telencephalon of C. batrachus.

Table 1: Numerical values of different parameters of multipolar neurons of C. batrachus in the lateral cortical area of telencephalon.

\begin{tabular}{clcc}
$\begin{array}{c}\text { S. } \\
\text { No. }\end{array}$ & Characteristics & & Numerical values \\
1 & Soma size & $\begin{array}{l}\text { Long axis } \\
\text { Short axis }\end{array}$ & $13.66 \pm 0.84 \mu \mathrm{m}$ \\
& & & $9.20 \pm 0.49 \mu \mathrm{m}$ \\
2 & Soma diameter & Apical dendrite & $10.25 \pm 1.19 \mu \mathrm{m}$ \\
3 & Dendritic thickness & Basal dendrite & $0.99 \pm 0.58 \mu \mathrm{m}$ \\
& & & $96.48 \pm 51.38 \mu \mathrm{m}$ \\
4 & Dendritic arborization & & $24.39 \pm 1.31 \mu \mathrm{m}$ \\
5 & Axonal length & & $4.86 \pm 1.41$ \\
6 & $\begin{array}{l}\text { Number of visible spines } \\
(n) / 10 \mu \mathrm{m} \text { length }\end{array}$ & & $17.88 \pm 1.46$ \\
7 & $\begin{array}{l}\text { True number of estimated } \\
\text { spines }(N) / 10 \mu \mathrm{m} \text { length }\end{array}$ & & \\
\hline
\end{tabular}

and pyramidal neurons and similarly as seen in visual wulst of birds where multipolar has maximum density [12]. However, in the case of reptiles [16], as well as in mammals [4], multipolar neurons are placed in the second position.

\subsection{Soma Shape and Size}

Table 1 shows the results (Fig. 2) of soma size (13.66 $\pm 0.84 \mu \mathrm{m}$ long axis and $9.20 \pm 0.49 \mu \mathrm{m}$ short axis) as well as $10.25 \pm 1.19$ $\mu \mathrm{m}$ soma diameter. Clarias batrachus have a short soma diameter than other vertebrates $[4,12,16,27]$. Biosynthetic and metabolic requirements of the entire cell with its dendritic arbor and axons determine the volume of neuronal soma [28]. Evolutionary enlargement of somata represents an increase in the thickness and ramifications of cell neuritis which might be playing a role in some aspects of locomotor adaptation [29]. Findings on soma shape show similarity with other vertebrates with a gradual increase in soma size from fish to mammal and all vertebrate fauna having an ovoidal, multiangular, polygonal, fusiform, and sometimes pearshaped multipolar soma $[4,12,16,27]$. 

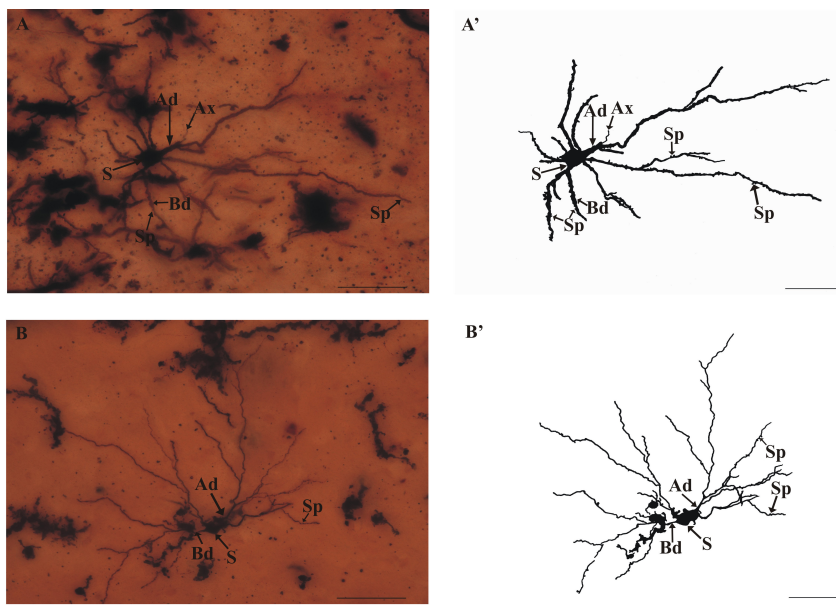

B'
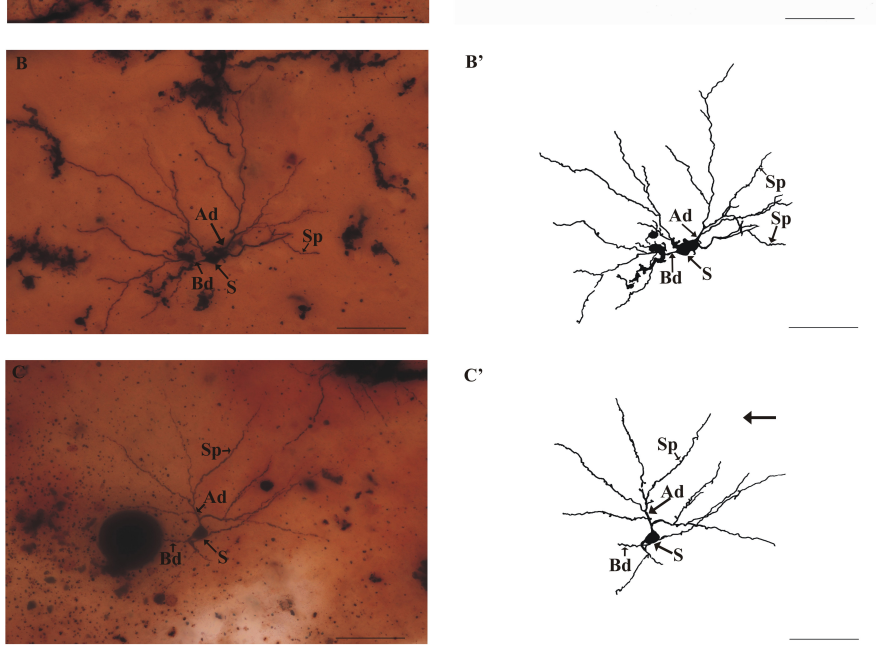

$C^{\prime}$

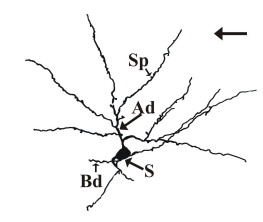

D'
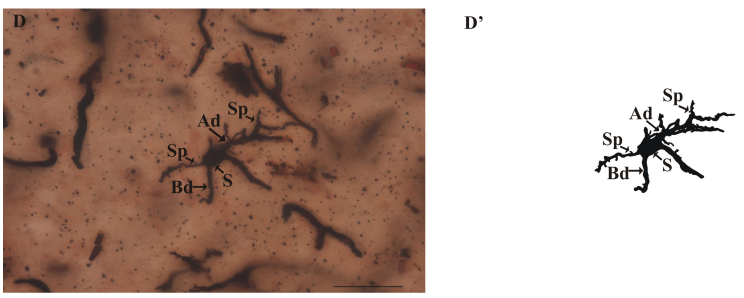

Figure 2: Multipolar neurons observed in the lateral cortical area of telencephalon of C. batrachus. (A-C), golgi-stained neurons and (A'-C') camera lucida of their corresponding golgi-stained neurons. $\mathrm{Ax}=$ axon; $\mathrm{Ad}=$ apical dendrite; $\mathrm{Bd}=$ basal dendrite; $\mathrm{S}=$ soma of neuron; and $\mathrm{Sp}=$ dendritic spine $($ scale bar $=50 \mu \mathrm{m})$.

\subsection{Dendritic Thickness}

The thickness of apical and basal dendrites are found to be 1.20 \pm 0.75 and $0.99 \pm 0.58 \mu \mathrm{m}$, respectively (Table 1 ), showing that apical dendrite is thicker than the basal dendrite (Fig. 2) with almost isotropic dendrites similarly as found in Apteronotus leptorhynchus [22]. There is a gradual increase observed in the thickness of dendrites (both apical and basal) in all the vertebrates $[4,13,16,27]$. Increased thickness in dendrites suggests an adaptive mechanism to support the increased number of spines over their surface for rapid neuronal transmission [12].

\subsection{Dendritic Arborization and Tree Shape}

The dendritic arborization mean value with standard deviation in C. batrachus is $96.48 \pm 51.38 \mu \mathrm{m}$ (Table 1) greater than $A$. leptorhynchus [22]. The maximum branching order of dendrite is four to eight, but it is three to four in Onchorhynchus keta [21]. Apical and basal dendrites ramify to give rise to secondary branches. Apical dendrites are those dendrites that are directed toward the upper or outer boundary of the lateral cortical area or directed toward the other cortical areas of the telencephalon and

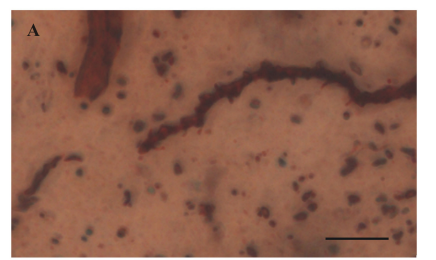

$\mathbf{A}^{\prime}$
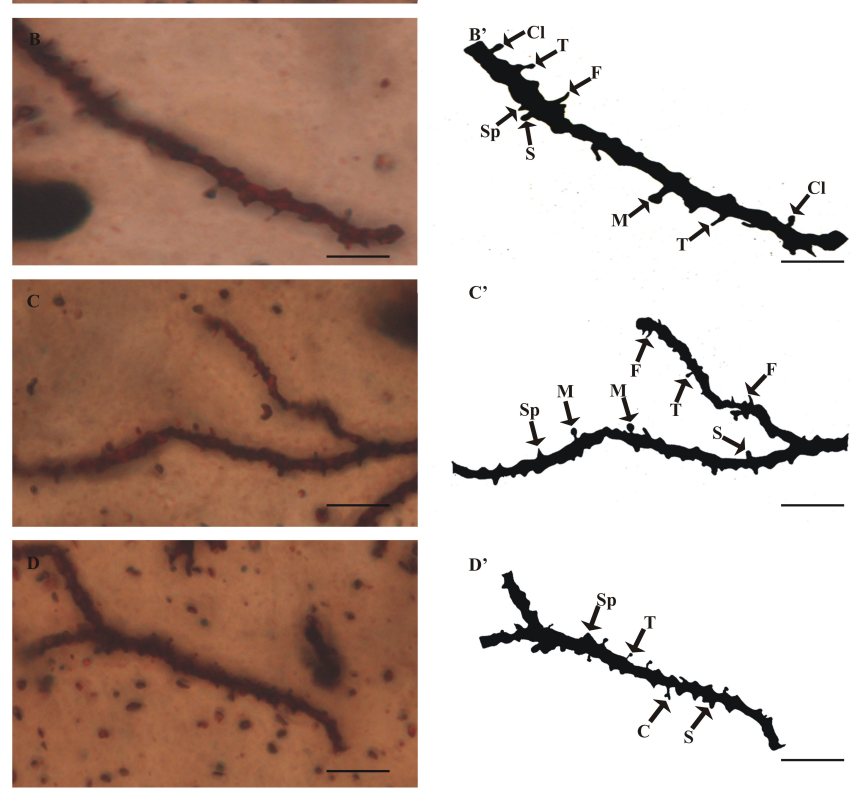

Figure 3: Morphology of dendritic spines in multipolar neurons of $C$. batrachus at a higher magnification. (A-D) golgi-stained dendrites of different multipolar neurons and (A'-D') camera lucida of their corresponding golgistained neurons. $\mathrm{C}=$ cup-shaped; $\mathrm{F}=$ filopodium; $\mathrm{Cl}=$ club-shaped; $\mathrm{M}=$ mushroom; $\mathrm{S}=$ stubby; $\mathrm{Sp}=$ spike; $\mathrm{T}=$ thin $($ scale bar $=20 \mu \mathrm{m})$.

making these neurons as projection type. Basal dendrites are those directed toward the dorso-central cortical area or the ventricle side in the presently studied fish. Some multipolar neurons are also found in the middle portion of the lateral cortical area which may serve as local circuit neurons or interneurons as reported in A. leptorhynchus [22] and in other vertebrates [11,13,24,30,31]. Multipolar projections create a circular to oblong or vertically elongated dendritic tree shape, while local circuit multipolar show a circular dendritic tree pattern in C. batrachus.

\subsection{Axonal Length}

The total observed mean length of the axon is $24.39 \pm 1.31 \mu \mathrm{m}$ (Table 1). The emergence position of an observed axon is not fixed in presently studied fish. Sometimes it is observed to emerge from the base of the soma and sometimes from the juxta somatic segment of the apical dendrite (Fig. 2A and A') and sometimes from the juxta somatic segment of the basal dendrite similar to that of $O$. keta [21]. Axon collaterals were not seen during the whole observation but in amphibians, a clear long axon was seen emerging from the soma without collaterals [32]. In reptiles, the axon emerges from the soma or adjacent to the primary dendrite and gives off several distal collaterals which run along with distances over the cell layer and deepest part of the inner plexiform layer $[16,17]$. In birds, the axon mostly originated from the cell body and turned ventrally to the fiber bundle and ran parallelly to the 
ventricle [33], while in mammals long steep axon originated from the soma and branched into several axon collaterals with axonal buttons [34].

\subsection{Dendritic Spine Density}

Dendritic spines are the small post-synaptic protuberance on dendrites (Figs. 2 and 3). Spine density was calculated by two methods in $10 \mu \mathrm{m}$ dendritic length. The first method is by counting the number of visible spines $(n)$ and the second method is the true number of estimated spines $(N)$ [26]. The visible spine density is $4.86 \pm 1.41$, while the true number of estimated spine density is $17.88 \pm 1.46$ in C. batrachus (Table 1). Spine density in $C$. batrachus is lower in comparison to other vertebrates [4,13,16,22] and can be correlated with its bottom-dwelling habit where mainly hypoxic condition is maintained [35]. In C. batrachus, the dendritic spines are very small, whereas in other vertebrates the dendritic spines are large. According to Harris et al. [36], large spines have large postsynaptic densities. By the study of spine density, it is concluded that over the dendritic field distribution of the spine on dendrites is uneven [37]. This finding is well in concordance with the present data on fish spine density which also shows an uneven distribution of spines on multipolar neurons. In C. batrachus, dendritic spines are mainly stubby, club-shaped, and various morphologies such as spike, mushroom, elongated clublike, stubby, thin, cup-shaped, filopodium, and elongated spine neck were seen in other vertebrates [13,38,39] (Fig. 3).

\section{CONCLUSION}

There are similarities of the result in this study with the results of studies conducted in one Chondrichthyes [20] and two Osteichthyes fish $[21,22]$. More studies are needed to address the correlation for the entire fish fauna. Multipolar neurons of the presently studied fish are to some extent similar in morphological basis with higher vertebrates and differ by having lower values of all the parameters studied such as long dendritic arborization and spine density. The differences in these neurons of the presently studied fish with other higher vertebrates are due to diverse physical characteristics and phylogenetic dissimilarities/deviation because they exploit a wide range of ecological prospects and inhabit a wide variety of niches. This variation of ecological prospect and niches has evolved several times due to adaptation in diverse environmental conditions [40]. Thus, morphological deviation of the neurons could be correlated with the adaptation and a consequence of phylogenetic divergence. The findings of the present work will provide a base for upcoming research by connecting the behavior of fish with this particular neuron.

\section{AUTHORS' CONTRIBUTIONS}

All authors made substantial contributions to the conception and design, acquisition of data, and analysis and interpretation of data; took part in drafting the article or revising it critically for important intellectual content; agreed to submit to the current journal; gave final approval of the version to be published; and agreed to be accountable for all aspects of the work.

\section{ETHICAL APPROVALS}

There is no fish-specific information on the guidelines of the Committee for the Purpose of Control and Supervision of Experiments on Animals, Ministry of Environment, Forest and Climate Change, Government of India, and it is not mandatory to get ethical clearance for fish in India. However, the guidelines for the care and use of animals were followed for the maintenance, handling, and conducting of the experimentation on fish.

\section{CONFLICT OF INTEREST}

The authors declare that they do not have any conflicts of interest.

\section{FUNDING}

The University Grants Commission, New Delhi, provided financial support in the form of a research fellowship.

\section{REFERENCES}

1. Takano T, Xu C, Funahashi Y, Namba T, Kaibuchi K. Neuronal polarization. Development 2015;142:2088-93.

2. Smith $\mathrm{PH}, \mathrm{Rhode}$ WS. Structural and functional properties distinguish two types of multipolar cells in the ventral cochlear nucleus. J Comp Neurol 1989;282:595-616.

3. Uchizono K. Characteristics of excitatory and inhibitory synapses in the central nervous system of the cat. Nature 1965;207:642-3.

4. Singh S, Chauhan P, Singh D, Srivastava UC. Distribution of nonpyramidal neurons in the frontal lobe of Indian gray mongoose (Herpestes edwardsii). Proc Natl Acad Sci India B 2016;88:209-17.

5. Ferrer I, Sancho S. Non-pyramidal neurons of layers I-III in the dog's cerebral cortex (Parietal Lobe). Acta Anat (Basel) 1987;129:43-52.

6. De Courten C, Garey LJ. Morphology of the neurons in the human lateral geniculate nucleus and their normal development. Exp Brain Res 1982;47:159-71

7. Wasilewska B, Najdzion J. Types of neurons of the claustrum in the rabbit-Nissl, Klüver-Barrera and Golgi studies. Folia Morphol 2001;60:41-5.

8. Butti C, Janeway CM, Townshend C, Wicinski BA, Reidenberg JS, Ridgway SH, et al. The neocortex of cetartiodactyls: I. A comparative Golgi analysis of neuronal morphology in the bottlenose dolphin (Tursiops truncatus), the minke whale (Balaenoptera acutorostrata), and the humpback whale (Megaptera novaeangliae). Brain Struct Funct 2015;220:3339-68.

9. Jacobs B, Lee L, Schall M, Raghanti MA, Lewandowski AH, Kottwitz JJ, et al. Neocortical neuronal morphology in the newborn giraffe (Giraffa Camelopardalis tippelskirchi) and African elephant (Loxodonta africana). J Comp Neurol 2016;524:257-87.

10. Montagnese CM, Krebs JR, Meyer G. The dorsomedial and dorsolateral forebrain of the zebra finch, Taeniopygia guttata: a Golgi study. Cell Tissue Res 1996;283:263-82.

11. Tömböl T, Davies DC, Nemeth A, Sebesteny T, Alpar A. A comparative Golgi study of chicken (Gallus domesticus) and homing pigeon (Columba livia) hippocampus. Anat Embryol 2000;201:85-101.

12. Srivastava UC, Gaur P. Naturally occurring neuronal plasticity in visual wulst of the Baya weaver, Ploceus philippinus (Linnaeus, 1766). Cell Tissue Res 2013;352:445-67.

13. Srivastava UC, Singh D, Kumar P. Neuronal classes and their specialization in the corticoid complex of a food-storing bird, the Indian house crow (Corvus splendens). Can J Zool 2014;92:423-32.

14. De La Iglesia JA, Lopez-Garcia C. A Golgi study of the principal projection neurons of the medial cortex of the lizard Podarcis hispanica. J Comp Neurol 1997;385:528-64. 
15. Srivastava UC, Maurya RC, Shishodiya UR. Cyto-architecture and morphology of the different neuronal types of the cerebral cortex of the Indian lizard, Mabouia carinata (Schneider). Proc Natl Acad Sci India Sect B 2007;77:331-47.

16. Srivastava UC, Maurya RC, Chand P. Cyto-architecture and neuronal types of the dorsomedial cerebral cortex of the common Indian wall lizard, Hemidactylus flaviviridis. Arch Ital Biol 2009;147:21-35.

17. Maurya RC, Srivastava UC. Neuronal morphology of dorsal cerebral cortex of the Indian wall lizard, H. flaviviridis (Rüppell). Asian J Exp Sci 2012;26:83-8.

18. Tóth P, Csank G, Lázár G. Morphology of the cells of origin of descending pathways to the spinal cord in Rana esculenta. A tracing study using cobaltic-lysine complex. J Hirnforschung 1985;26: 365-83.

19. Lázár G, Kozicz T. Morphology of neurons and axon terminals associated with descending and ascending pathways of the lateral forebrain bundle in Rana esculenta. Cell Tissue Res 1990;260: 535-48.

20. Manso MJ, Anadón R. Golgi study of the telencephalon of the small-spotted dogfish Scyliorhinuscanicula L. J Comp Neurol 1993;333:485-502.

21. Pushchina EV, Varaksin AA, Romanov NS. Neuronal organization of the telencephalon in the Chum Salmon Onchorhynchus keta. Russ J Mar Biol 2003;29:362-7.

22. Giassi AC, Harvey-Girard E, Valsamis B, Maler L. Organization of the gymnotiform fish pallium in relation to learning and memory: I. Cytoarchitectonics and cellular morphology. J Comp Neurol 2012;520:3314-37.

23. Portavella M, Vargas JP. Emotional and spatial learning in goldfish is dependent on different telencephalic pallial systems. Eur J Neurosci 2005;2:2800-6.

24. Schwerdtfeger WK, Buhl E. Various types of non-pyramidal hippocampal neurons project to the septum and contralateral hippocampus. Brain Res 1986;386:146-54.

25. Debnath S. Clarias batrachus, the medicinal fish: an excellent candidate for aquaculture \& employment generation. In International Conference on Asia Agriculture and Animal. IPCBEE (13), Singapore, pp 32-7, 2011.

26. Feldman ML, Peters A. A technique for estimating total spine numbers on Golgi-impregnated dendrites. J Comp Neurol 1979;188:527-42.

27. Fasolo A, Franzoni MF. A Golgi study on the hypothalamus of amphibia. Cell Tissue Res 1977;178:341-54.

28. Kaas JH. Why is brain size so important: design problems and solutions as neocortex gets biggeror smaller. Brain Mind 2000;1:7-23.

29. Sherwood CC, Lee PW, Rivara CB, Holloway RL, Gilissen EP, Simmons RM, et al. Evolution of specialized pyramidal neurons in primate visual and motor cortex. Brain Behav Evol 2003;61:28-44.
30. Ferrer I, Fabregues I, Condom E. A Golgi study of the sixth layer of the cerebral cortex. II. The gyrencephalic brain of Carnivora, Artiodactyla and Primates. J Anat 1986;146:87-104.

31. De La Iglesia JA, Lopez-Garcia C. A Golgi study of the short-axon interneurons of the cell layer and inner plexiform layer of the medial cortex of the lizard Podarcishispanica. J Comp Neurol 1997;385: 565-98.

32. Capanna E, Clairambault P. Neuronal typology in the anuran telencephalon: a Golgi study. Cells Tissues Organs 1974;89:321-32.

33. Srivastava UC, Chand P, Maurya RC. Cytoarchitectonic organization and morphology of the cells of hippocampal complex in strawberry finch, Estrildaamandava. Cell Mol Biol 2007;53:103-20.

34. Somogyi P, Freund TF, Cowey A. The axo-axonic interneuron in the cerebral cortex of the rat, cat and monkey. Neuroscience 1982;7:2577607.

35. Hossein-Javaheri N, Wilkie MP, Lado WE, Buck LT. Stellate and pyramidal neurons in goldfish telencephalon respond differently to anoxia and GABA receptor inhibition. J Exp Biol 2017;220:695-704.

36. Harris KM, Jensen FE, Tsao B. Three-dimensional structure of dendritic spines and synapses in rat hippocampus (CA1) at postnatal day 15 and adult ages: implications for the maturation of synaptic physiology and long-term potentiation. J Neurosci 1992;12:2685-705.

37. Horner $\mathrm{CH}$, Arbuthnott E. Methods of estimation of spine density-are spines evenly distributed throughout the dendritic field? J Anat 1991;177:179-84.

38. Maiti P, Manna J, Ilavazhagan G, Rossignol J, Dunbar GL. Molecular regulation of dendritic spine dynamics and their potential impact on synaptic plasticity and neurological diseases. Neurosci Biobehav Rev 2015;59:208-37.

39. Srivastava UC, Sakal ID, Maurya RC. Differences between dendritic spines of neurons of different regions of the cerebral cortex of the garden Lizard, C. versicolor (Daudin). Proc Natl Acad Sci India B 2012;82:307-16.

40. Wellborn GA, Langerhans RB. Ecological opportunity and the adaptive diversification of lineages. Ecol Evol 2015;5:176-95.

\section{How to cite this article:}

Mohanty B, Ojha AK. Morphological status of multipolar neurons in the lateral cortical area of the telencephalon of a catfish, Clarias batrachus: A Golgi study. J Appl Biol Biotech 2021; 9(05):78-82. 